\title{
Supplementation of Diet With Galacto- oligosaccharides Increases Bifidobacteria, but Not Insulin Sensitivity, in Obese Prediabetic Individuals
}

Citation for published version (APA):

Canfora, E. E., van der Beek, C. M., Hermes, G. D. A., Goossens, G. H., Jocken, J. W. E., Holst, J. J., van Eijk, H. M., Venema, K., Smidt, H., Zoetendal, E. G., Dejong, C. H. C., Lenaerts, K., \& Blaak, E. E. (2017). Supplementation of Diet With Galacto-oligosaccharides Increases Bifidobacteria, but Not Insulin Sensitivity, in Obese Prediabetic Individuals. Gastroenterology, 153(1), 87-97.e3.

https://doi.org/10.1053/j.gastro.2017.03.051

Document status and date:

Published: 01/07/2017

DOI:

10.1053/j.gastro.2017.03.051

Document Version:

Publisher's PDF, also known as Version of record

Document license:

Taverne

Please check the document version of this publication:

- A submitted manuscript is the version of the article upon submission and before peer-review. There can be important differences between the submitted version and the official published version of record.

People interested in the research are advised to contact the author for the final version of the publication, or visit the DOI to the publisher's website.

- The final author version and the galley proof are versions of the publication after peer review.

- The final published version features the final layout of the paper including the volume, issue and page numbers.

Link to publication

\footnotetext{
General rights rights.

- You may freely distribute the URL identifying the publication in the public portal. please follow below link for the End User Agreement:

www.umlib.nl/taverne-license

Take down policy

If you believe that this document breaches copyright please contact us at:

repository@maastrichtuniversity.nl

providing details and we will investigate your claim.
}

Copyright and moral rights for the publications made accessible in the public portal are retained by the authors and/or other copyright owners and it is a condition of accessing publications that users recognise and abide by the legal requirements associated with these

- Users may download and print one copy of any publication from the public portal for the purpose of private study or research.

- You may not further distribute the material or use it for any profit-making activity or commercial gain

If the publication is distributed under the terms of Article $25 \mathrm{fa}$ of the Dutch Copyright Act, indicated by the "Taverne" license above, 


\title{
Supplementation of Diet With Galacto-oligosaccharides Increases Bifidobacteria, but Not Insulin Sensitivity, in Obese Prediabetic Individuals
}

\author{
Emanuel E. Canfora, ${ }^{1,2, *}$ Christina M. van der Beek, ${ }^{1,3, *}$ Gerben D. A. Hermes, ${ }^{1,4}$ \\ Gijs H. Goossens, ${ }^{1,2}$ Johan W. E. Jocken,, ${ }^{1,2}$ Jens J. Holst, ${ }^{5,6}$ Hans M. van Eijk, ${ }^{3}$ \\ Koen Venema, ${ }^{1,7}$ Hauke Smidt, ${ }^{1,4}$ Erwin G. Zoetendal, ${ }^{1,4}$ Cornelis H. C. Dejong, ${ }^{1,3,8}$ \\ Kaatje Lenaerts, ${ }^{1,3}$ and Ellen E. Blaak ${ }^{1,2}$
}

\begin{abstract}
${ }^{1}$ Top Institute Food and Nutrition, Wageningen, The Netherlands; ${ }^{2}$ Department of Human Biology, ${ }^{3}$ Department of Surgery, NUTRIM School of Nutrition and Translational Research in Metabolism, Maastricht University Medical Centre+, Maastricht, The Netherlands; ${ }^{4}$ Laboratory of Microbiology, Wageningen University, Wageningen, The Netherlands; ${ }^{5}$ Novo Nordisk Foundation Center for Basic Metabolic Research, University of Copenhagen, Copenhagen, Denmark; ${ }^{6}$ Department of Biomedical Sciences, The Panum Institute, University of Copenhagen, Copenhagen, Denmark; 'Beneficial Microbes Consultancy, Wageningen, The Netherlands; ${ }^{8}$ Department of Surgery, Universitätsklinikum Aachen, Aachen, Germany
\end{abstract}

BACKGROUND \& AIMS: The gut microbiota affects host lipid and glucose metabolism, satiety, and chronic low-grade inflammation to contribute to obesity and type 2 diabetes. Fermentation end products, in particular the short-chain fatty acid (SCFA) acetate, are believed to be involved in these processes. We investigated the long-term effects of supplementation with galacto-oligosaccharides (GOS), an acetogenic fiber, on the composition of the human gut microbiota and human metabolism. METHODS: We performed a double-blinded, placebo-controlled, parallel intervention study of 44 overweight or obese (body mass index, $28-40 \mathrm{~kg} / \mathrm{m}^{2}$ ) prediabetic men and women (ages, 45-70 y) from October 2014 through October 2015 in Maastricht, The Netherlands. The participants were assigned randomly to groups who ingested $15 \mathrm{~g}$ GOS or isocaloric placebo (maltodextrin) daily with their regular meals for 12 weeks. Before and after this period, we collected data on peripheral and adipose tissue insulin sensitivity, fecal microbiota composition, plasma and fecal SCFA, energy expenditure and substrate oxidation, body composition, and hormonal and inflammatory responses. The primary outcome was the effect of GOS on peripheral insulin sensitivity, measured by the hyperinsulinemic-euglycemic clamp method. RESULTS: Supplementation of diets with GOS, but not placebo, increased the abundance of Bifidobacterium species in feces by 5 -fold $(P=.009 ; \mathrm{q}=0.144)$. Microbial richness or diversity in fecal samples were not affected. We did not observe any differences in fecal or fasting plasma SCFA concentrations or in systemic concentrations of gut-derived hormones, incretins, lipopolysaccharide-binding protein, or other markers of inflammation. In addition, no significant alterations in peripheral and adipose tissue insulin sensitivity, body composition, and energy and substrate metabolism were found. CONCLUSIONS: Twelveweek supplementation of GOS selectively increased fecal Bifidobacterium species abundance, but this did not produce significant changes in insulin sensitivity or related substrate and energy metabolism in overweight or obese prediabetic men and women. ClincialTrials.gov number, NCT02271776.

Keywords: Short-Chain Fatty Acids; Prebiotics; Microbial Obesity; Metabolic Control.
A ccumulating evidence indicates that the human gut A microbiota is involved in the etiology of obesity and type 2 diabetes. ${ }^{1-3}$ Several strategies to manipulate gut microbiota composition including fecal transplantation, antibiotic treatment, as well as supplementation of probiotics and prebiotics have indicated that alterations in the microbial composition and diversity might lead to changes in insulin sensitivity and metabolic profile in human beings, ${ }^{4-7}$ although data are not consistent. ${ }^{8-10}$ Importantly, however, long-term dietary intervention studies in human beings, combining microbiota analysis with detailed metabolic phenotyping, are scarce, and putative underlying mechanisms for beneficial effects on host metabolism remain to be fully elucidated.

Many data on prebiotic effects of dietary fibers are derived from studies with either inulin-type fructo-oligosaccharides or galacto-oligosaccharides (GOS). ${ }^{11}$ These dietary fibers have the capacity to selectively alter the gut microbiota composition and stimulate the growth of putatively beneficial bacterial genera such as Bifidobacterium and Lactobacillus. ${ }^{11,12}$ GOS is a soluble dietary fiber derived from $\beta$-galactosidase-induced conversion of lactose. A limited number of human studies have indicated beneficial metabolic effects of GOS. ${ }^{13,14}$ Twelve-week supplementation of a GOS mixture to overweight participants improved insulin and lipid homeostasis, and attenuated low-grade systemic inflammation in these participants. ${ }^{13}$

\section{*Authors share co-first authorship.}

Abbreviations used in this paper: BMI, body mass index; CID, clinical investigation day; FFA, free fatty acid; GLP-1, glucagon-like peptide-1; GOS, galacto-oligosaccharides; HITChip, Human Intestinal Tract Chip; IL, interleukin; LBP, lipopolysaccharide-binding protein; PYY, peptide YY; RIA, radioimmunoassay; SCFA, short-chain fatty acid; TAG, triacylglycerol; TNF- $\alpha$, tumor necrosis factor- $\alpha$.

Most current article

\section{(C) 2017 by the AGA Institute} 0016-5085/\$36.00

http://dx.doi.org/10.1053/j.gastro.2017.03.051 


\section{EDITOR'S NOTES}

\section{BACKGROUND AND CONTEXT}

Accumulating data, mainly derived from rodent studies, indicate that gut microbiota are involved in the etiology of obesity and insulin resistance, possibly by fermentation of prebiotics into short-chain fatty acids (SCFA). However, human studies are lacking.

\section{NEW FINDINGS}

12-week supplementation of the prebiotic galactooligosaccharides consistently increased bifidobacteria, in obese, prediabetic individuals, but did not alter SCFA concentrations, insulin sensitivity, or energy metabolism.

\section{LIMITATIONS}

This study did not measure whether postprandial metabolism is affected by the prebiotic treatment.

\section{IMPACT}

A change in microbial composition towards the more favorable bifidobacteria does not automatically lead to beneficial effects on human metabolism.

Furthermore, dietary supplementation of a GOS mixture to healthy elderly volunteers altered gut microbiota composition and improved systemic and fecal inflammatory markers. ${ }^{14}$ However, mechanisms involved in these metabolic effects were not determined in these studies. One of the important mechanisms involved in the effects of prebiotic fibers on metabolic health is their fermentation by the gut microbiota, resulting in the formation of short-chain fatty acids (SCFAs), mainly acetate, propionate, and butyrate. ${ }^{15}$

We recently showed that acute infusion of acetate into the distal part of the colon led to increased systemic acetate concentrations, increased fat oxidation, and circulating concentrations of the satiety-stimulating hormone peptide YY (PYY) in overweight men. ${ }^{16}$ Based on that, we hypothesized that long-term supplementation of a high-acetogenic fiber would result in increased circulating acetate availability and an improved metabolic profile. Increased acetate concentrations were found after in vitro fermentation of GOS. ${ }^{17}$ In accordance, a 6-week supplementation of GOS to infants increased fecal acetate concentrations and fecal abundance of Bifidobacterium. ${ }^{18}$ Several members of colonic microbiota are involved in GOS fermentation, of which bifidobacteria mainly are responsible. ${ }^{19}$ As such, bifidobacteria convert polysaccharides into mainly lactate and acetate $^{20}$ Therefore, long-term GOS intake may beneficially may modulate the gut microbiota composition and induce acetate production, leading to improved host energy and improved substrate metabolism and insulin sensitivity. Hence, the present study investigated the effects of 12 -week GOS supplementation on peripheral insulin sensitivity in overweight and obese prediabetic men and postmenopausal women. Secondary outcomes were effects of GOS supplementation on fecal microbiota composition, plasma and fecal SCFA concentrations, body composition, energy expenditure and substrate oxidation, circulating metabolites, hormones, inflammatory markers, and adipokine concentrations.

\section{Materials and Methods}

\section{Study Participants}

Forty-six overweight and obese (body mass index [BMI], $28-40 \mathrm{~kg} / \mathrm{m}^{2}$ ) Caucasian men and postmenopausal women, aged 45-70 years, with impaired fasting glucose and/or impaired glucose tolerance were recruited between October 2014 and October 2015 from the vicinity of Maastricht, The Netherlands. Impaired fasting glucose was defined as fasting plasma glucose levels $\geq 5.6 \mathrm{mmol} / \mathrm{L}$. Impaired glucose tolerance was defined as plasma glucose levels between 7.8 and 11 $\mathrm{mmol} / \mathrm{L}$ at 2 hours after oral ingestion of $75 \mathrm{~g}$ glucose dissolved in $250 \mathrm{~mL}$ tap water (oral glucose tolerance test). Volunteers had to be weight-stable for at least 3 months before study participation. Exclusion criteria for participation in the study were as follows: diagnosis of diabetes mellitus; gastroenterologic diseases or prior abdominal surgery; cardiovascular diseases; liver or kidney malfunction; patients with a life expectancy shorter than 5 years; participants following a hypocaloric diet; or use of antibiotics, prebiotics, or probiotics in the 3 months before the start of the study or during the study period. Participants did not use $\beta$-blockers, lipid- or glucose-lowering drugs, anti-oxidants, or chronic corticosteroids. The study was approved by the Medical Ethical Committee of Maastricht University Medical Centre+ and was conducted in accordance with the Declaration of Helsinki (revised version, October 2008, Seoul, South Korea). Written informed consent was obtained from all participants. All authors had access to the study data and reviewed and approved the final manuscript.

\section{Study Design}

This study was a double-blind, placebo-controlled, randomized, parallel trial. After stratification for sex and age, an independent researcher randomized subjects into the GOS or placebo group. Participants in the intervention group were asked to ingest 7.04 g of Vivinal GOS powder (FrieslandCampina Domo, Amersfoort, The Netherlands), containing 5 g GOS, 3 times per day with their regular meals during the 12 -week intervention period (Supplementary Figure 1). Besides 69\% GOS, the product contained 23\% lactose, 5\% monosaccharides (glucose and galactose), and 3\% moisture. Participants in the placebo group were asked to ingest $5.65 \mathrm{~g}$ of maltodextrin (Avebe, Veendam, The Netherlands) 3 times per day with their regular meals during 12 weeks. The amount of maltodextrin was isocaloric to the amount of Vivinal GOS powder product (269.6 kJ/day). GOS and maltodextrin were both provided as white powdered supplements. The products were provided in sachets and were consumed with a low-fat yogurt drink (Optimel Drink Lang Lekker $200 \mathrm{~mL}$; FrieslandCampina, Amersfoort, The Netherlands). There were no probiotic strains or supplemented GOS in the yogurt drink. The participants were instructed to document their GOS or placebo intake in a daily diary and had to return all sachets to assess compliance. All participants were instructed to continue their usual physical activity and dietary regimen throughout the whole intervention period to study the isolated effect of the differential supplementation.

The primary outcome of the study was the effect of GOS on peripheral insulin sensitivity as measured by the hyperinsulinemic-euglycemic clamp method. Secondary outcomes were substrate oxidation and energy expenditure, fecal 
microbiota composition, fecal and plasma SCFA, circulating metabolites (glucose, triacylglycerol [TAG], free fatty acids [FFA], free glycerol) and hormones (insulin, PYY, glucagon-like peptide-1 [GLP-1], leptin), plasma inflammatory markers (tumor necrosis factor- $\alpha$ [TNF- $\alpha]$, interleukin [IL]6, IL8, lipopolysaccharide binding protein [LBP]), body composition, BMI, body weight, dietary intake, and physical activity.

Before and directly after the 12 -week intervention period, participants underwent an experimental clinical investigation day (CID). The 12-week intervention started the day after the first CID. During the 3 days before the CID participants recorded their dietary intake and level of physical activity. In addition, fecal samples were collected 1 day before the CID.

\section{Dietary Intake and Physical Activity Recording}

Participants were asked to complete a 3-day dietary record before the intervention period, in week 6 and in week 12 of the intervention. Before the start of the intervention, participants were instructed by a dietician how to weigh and record their food and beverage intake. The volunteers were asked to include 2 weekdays and 1 weekend day in the 3 -day period. The dietary records were checked, discussed in case of missing data, and analyzed by an experienced dietician. Energy and nutrient intake were analyzed using the Dutch Food Composition Dataset (Nederlands Voedingsstoffenbestand, National Institute for Public Health and Environment, Ministry of Health, Welfare and Sport, The Hague, The Netherlands).

Self-reported level of physical activity was assessed using the Short Questionnaire to Assess Health enhancing physical activity. ${ }^{21}$ Participants completed the questionnaire before the intervention period and in week 6 and week 12 of the intervention period. Outcome value was the time spent (minutes) in light, moderate, and vigorous physical activity based on metabolic equivalent, as reported before. ${ }^{21}$

\section{$C I D$}

Two days before the CID, participants were asked to refrain from intense physical activity and alcohol consumption. In the evening before each CID, the volunteers consumed a standardized low-fiber meal (62 energy \% carbohydrate, 24 energy $\%$ protein, and 14 energy \% fat). Participants came to the laboratory by car or public transport in the morning after an overnight fast (12 h). All procedures were performed with the participant in a resting, half-supine position. During the CID, several measurements took place. Each CID started with a dualenergy X-ray absorptiometry scan to determine body composition and measurements of body weight and height. Subsequently, a 1-step hyperinsulinemic-euglycemic clamp was performed to measure peripheral insulin sensitivity, combined with indirect calorimetry to measure substrate oxidation and energy expenditure during fasting and euglycemic conditions. In addition, blood samples were taken at different time points during fasting and euglycemic conditions (Supplementary Figure 1).

Body composition. Body fat percentage, body fat, and visceral fat distribution, as well as lean mass, were measured before and after the intervention period by use of a dual-energy X-ray absorptiometry scan using a 3-compartment model (Hologic BCA; VitaK, Maastricht, The Netherlands). In addition, fasting body weight (in underwear using a calibrated weight scale) and height (barefoot) were measured to calculate BMI.

One-step hyperinsulinemic-euglycemic clamp. A hyperinsulinemic-euglycemic clamp was performed to measure whole-body insulin-stimulated glucose rate of disappearance. Participants were placed in a semirecumbent position. First, a Teflon cannula (Becton Dickinson, Franklin Lakes, NJ) was inserted into an antecubital vein for infusion of glucose and insulin. To measure blood glucose, a second Teflon cannula was inserted into a superficial dorsal hand vein for sampling of blood (1 $\mathrm{mL}$ every $5 \mathrm{~min}$ ), which was arterialized by placing the hand into a hotbox, blowing warm air $\left(\sim 50^{\circ} \mathrm{C}\right)$. A priming dose of insulin infusion (Actrapid; Novo Nordisk, Gentofte, Denmark) was administered during the first 10 minutes ( $\mathrm{t} 0-\mathrm{t} 10 \mathrm{~min}$ ) and insulin infusion was continued thereafter at $40 \mathrm{mU} / \mathrm{m}^{2} / \mathrm{min}$ for 2 hours (t10-t120 min). By variable infusion of a $17.5 \%$ glucose solution, plasma concentrations were maintained at $5.0 \mathrm{mmol} / \mathrm{L}$. The mean glucose infusion rate during the final 30 minutes of euglycemia was used as an indicator of the peripheral insulin sensitivity and defined as the $\mathrm{M}$ value. ${ }^{22}$ In addition, during fasting conditions (t-30-t0 $\mathrm{min}$ ) and during the 30-minute steady state of the clamp (t90-t120 min), energy expenditure and substrate oxidation were measured using indirect calorimetry. Additional blood plasma samples were taken during fasting (t-5 min) and euglycemic (t90 and $\mathrm{t} 120 \mathrm{~min}$ ) conditions.

Insulin-stimulated suppression of circulating FFA was measured as an indicator of adipose tissue insulin sensitivity. Insulin-stimulated FFA suppression percentage was calculated by the following formula: ([baseline FFA - insulin-stimulated FFA during steady state clamp] / baseline FFA). ${ }^{23}$

Indirect calorimetry. For indirect calorimetry, an opencircuit ventilated hood system (Omnical; Medical Ethical Committee of Maastricht University Medical Centre+, Maastricht, The Netherlands) was used. $\mathrm{CO}_{2}$ production (carbon dioxide output per unit of time in $\mathrm{L} / \mathrm{min}$ ) and $\mathrm{O}_{2}$ consumption (oxygen consumption per unit of time in $\mathrm{L} / \mathrm{min}$ ) were measured during 2 investigational time periods: a baseline measurement of 30 minutes before start of the clamp (t-30-t0 $\mathrm{min}$ ) and for 30 minutes during the steady-state of the hyperinsulinemiceuglycemic clamp (t90-t120 min). The equations of Weir ${ }^{24}$ and Frayn $^{25}$ were used to calculate resting energy expenditure and the rate of fat and carbohydrate oxidation.

Blood collection, storage, and biochemical analyses. Blood was collected in ice-cold EDTA tubes $(0.2$ mol/L EDTA; Sigma, Dorset, UK) for SCFA, insulin, glucose, FFA, TAG, free glycerol, leptin, LBP, TNF- $\alpha$, IL6, and IL8 analyses during fasting ( $\mathrm{t}-5 \mathrm{~min}$ ) and euglycemic ( $\mathrm{t} 90$ and $\mathrm{t} 120$ min) conditions. For GLP-1 analysis, blood was collected in a 2-mL EDTA tube containing $20 \mu \mathrm{L}$ of dipeptidyl peptidase-IV inhibitor (Millipore, Darmstadt, Germany). For PYY analysis, blood was collected in a 2-mL aprotinin tube containing $20 \mu \mathrm{L}$ of dipeptidyl peptidase-IV inhibitor. The samples were centrifuged at $3500 \mathrm{~g}$, at $4^{\circ} \mathrm{C}$ for 10 minutes, and plasma was aliquoted and directly snap-frozen in liquid nitrogen and stored at $-80^{\circ} \mathrm{C}$ until analysis.

Plasma FFA, TAG, and glucose were measured with enzymatic assays on an automated spectrophotometer (ABX Pentra 400 autoanalyzer; Horiba ABX, Montpellier, France). Plasma-free glycerol was measured after precipitation with an enzymatic assay (Enzytec Glycerol; Roche Biopharm, Basel, Switzerland) automated on a Cobas Fara spectrophotometric autoanalyzer (Roche Diagnostics, Basel, Switzerland). The concentrations of 
insulin, leptin, and PYY were determined with commercially available radioimmunoassay (RIA) kits (human insulin-specific RIA, human leptin RIA, human PYY [3-36] RIA; Millipore Corporation, Billerica, MA). IL6, IL8, and TNF- $\alpha$ were determined with an enzyme-linked immunosorbent assay kit (Human ProInflammatory II 4-Plex Ultra-Sensitive Kit; Meso Scale Diagnostics, Rockville, MD). Plasma samples were assayed for total GLP-1 immunoreactivity using an antiserum that reacts equally with intact GLP-1 and the primary (N-terminally truncated) metabolite as previously described. ${ }^{26}$ For the detection of LBP, plates (Greiner Microlon 600 high binding; Sigma Aldrich, St. Louis, MO) were coated with polyclonal anti-human LBP antibodies. Diluted plasma samples (1:5000) and a standard dilution series with recombinant LBP were added to the plate. Detection occurred with a biotinylated polyclonal rabbit anti-human LBP IgG, followed by peroxidase-conjugated streptavidin and substrate. The detection limit for the LBP assay was $200 \mathrm{pg} / \mathrm{mL}^{27}$

SCFA analysis. Feces was collected at home, starting from 2 days before the test days and stored in the subject's freezer at $-20^{\circ} \mathrm{C}$, transported on dry ice, and stored on arrival at the university at $-80^{\circ} \mathrm{C}$. Fecal acetate, propionate, and butyrate were measured by gas chromatography-mass spectrometry (Dr. Stein and Collegae Medical Laboratory, Mönchengladbach, Germany), according to the method described by Garciá-Villalba et al. ${ }^{27}$ Storage and processing of plasma samples for analysis of SCFA was performed as reported before. ${ }^{28}$ Analysis of these samples was performed using liquid chromatography-mass spectrometry, enabling lower detection limits for acetate, propionate, and butyrate of $0.1,0.05$, and $0.05 \mu \mathrm{mol} / \mathrm{L}$, respectively.

Microbiota composition. DNA was isolated from feces using the repeated bead-beating method as previously described, $^{29}$ and subsequently used for microbiota profiling using the Human Intestinal Tract Chip (HITChip), a phylogenetic microarray based on $16 \mathrm{~S}$ ribosomal RNA gene sequences of more than 1000 intestinal bacterial phylotypes. ${ }^{30}$ In short, $16 \mathrm{~S}$ ribosomal RNA genes were amplified by polymerase chain reaction, followed by in vitro transcription, Cy3/Cy5 labeling and fragmentation of RNA, and hybridization. Duplicate hybridizations with a Pearson correlation of more than $98 \%$ were considered for further analysis, and microbiota profiles were generated by preprocessing of probe-level measurements with minimum-maximum normalization and the frozen-robust probabilistic averaging probe summarization ${ }^{31}$ into 3 phylogenetic levels: order-like, genus-like ( $>90 \%$ sequence similarity), and phylotype-like ( $>98 \%$ sequence similarity). ${ }^{30}$ In the present work, our analysis focused on the genus-level variation.

\section{Statistical Analysis}

To detect a physiologically relevant difference in the change in peripheral insulin sensitivity of $20 \%$ with a SD of 4 , a power of $80 \%$ and assuming an $\alpha$ value of .05, a number of at least 17 participants per group was necessary. Because an equivalent subject number for men and women was required, 18 participants per group ( 9 men and 9 women per group) were needed. Assuming a $25 \%$ drop-out rate, the planned recruitment was $\mathrm{N}=46$ participants in total.

All data are expressed as means \pm SD. Baseline differences were evaluated using a Student unpaired $t$ test. Body composition data and metabolic variables were first tested for normality using the Shapiro-Wilk test and showed a normal distribution. A 2-factor repeated-measures analysis of variance with time (before, after) and intervention (GOS, placebo) as factor was applied. In case of significant time $\times$ intervention interaction, post hoc analyses with Bonferroni correction were applied to identify significant within-intervention effects. Statistics were performed using SPSS 22.0 (IBM, Armonk, NY) and a $P$ value less than .05 (2-sided $P$ value) was considered statistically significant.

For HITChip analysis, $\log _{10}$-transformed signals were used as a proxy for bacterial logarithmic abundance. To determine the treatment effect on the abundance of genus-level microbial groups within individuals and the contrast between the 2 treatment groups, a linear mixed model taking into account the effects of repeated measurements, treatment group, age, and BMI using the lme4 package was used. ${ }^{32}$ Diversity of the microbiota was quantified based on nonlogarithmized HITChip oligo-level signals by the inverse Simpson index using the Vegan package (https://cran.r-project.org/web/packages/ vegan/vegan.pdf). ${ }^{33,34}$ Analysis of variance with the Tukey

Table 1.Study Participant Baseline Characteristics $(\mathrm{N}=44)$

\begin{tabular}{lccc}
\hline \multicolumn{1}{c}{ Variable } & GOS $(\mathrm{n}=21)$ & Placebo $(\mathrm{n}=23)$ & $P$ value \\
\hline Sex, male/female & $11 / 10$ & $12 / 11$ \\
IGT/IFG/IGT + IFG, $\mathrm{n}$ & $0 / 14 / 7$ & $2 / 15 / 6$ & $58.4 \pm 7.3$ \\
Age, $y$ & $59.2 \pm 7.2$ & $96.9 \pm 11.5$ & .716 \\
Weight, $\mathrm{kg}$ & $98.4 \pm 11.9$ & $173.5 \pm 7.5$ & .263 \\
Height, $\mathrm{Cm}$ & $172.0 \pm 7.2$ & $32.3 \pm 3.5$ & .525 \\
Body mass index, $\mathrm{kg} / \mathrm{m}^{2}$ & $33.3 \pm 3.7$ & $1.0 \pm 0.06$ & .321 \\
Waist-hip ratio & $1.0 \pm 0.06$ & $127 \pm 15$ & .899 \\
Systolic blood pressure, $\mathrm{mm} \mathrm{Hg}$ & $129 \pm 11$ & $85 \pm 10$ & .742 \\
Diastolic blood pressure, $\mathrm{mm} \mathrm{Hg}$ & $86 \pm 7$ & $5.8 \pm 0.4$ & .779 \\
Fasting glucose level, $\mathrm{mmol} / \mathrm{L}$ & $6.0 \pm 0.5$ & $7.0 \pm 2.0$ & .095 \\
OGTT 2-h plasma glucose, $\mathrm{mmol} / \mathrm{L}$ & $6.4 \pm 1.7$ & $19.1 \pm 7.2$ & .259 \\
Fasting insulin level, $\mathrm{uU} / \mathrm{mL}$ & $20.7 \pm 6.7$ & $5.10 \pm 2.7$ & .721 \\
HOMA-IR & $5.34 \pm 2.7$ & $5.6 \pm 0.4$
\end{tabular}

NOTE. Values are given as means \pm SD. Data were analyzed using the Student unpaired $t$ test.

IFG, impaired fasting glucose; IGT, impaired glucose tolerance; HOMA-IR, homeostatic model assessment of insulin resistance; OGTT, oral glucose tolerance test. 
Honest Significant post hoc analysis was applied to compare diversity between and within groups. $P$ values were corrected for multiple comparisons using the Benjamini-Hochberg procedure. HITChip statistics were performed using R v3.1.3 software (The $\mathrm{R}$ Foundation for Statistical Computing, Vienna, Austria). A corrected $q$ value of less than 0.2 was considered significant.

\section{Results}

Forty-six volunteers started with the 12-week intervention period. Two women dropped out of the study because of the use of antibiotics during the study period (1 for a wound infection after a bicycle fall and 1 for a lower respiratory tract infection) (Supplementary Figure 2). Therefore, a total of 44 participants completed the study and their baseline characteristics are shown in Table 1. No significant differences were found between groups at baseline. Compliance was confirmed by counting returned empty sachets $(245 \pm 11$ of $251 \pm 7.6$ sachets [97.6\%] returned empty) in comparison with the given amounts of the daily diary product. No adverse events were reported. Importantly, participants reported no side effects of GOS or placebo treatment, such as changes in stool frequency or gastrointestinal complaints.

\section{Fecal Microbiota}

Twelve-week GOS supplementation consistently increased fecal Bifidobacterium by $5.0- \pm 0.3$-fold $(P=.009$; $\mathrm{q}=0.144$ ) (Figure 1) compared with placebo. Other taxa whose abundance was impacted differentially by the GOS intervention compared with placebo were Prevotella oralis et rel. by $1.14- \pm 0.6$-fold $(P=.010 ; \mathrm{q}=0.144)$ and Prevotella melaninogenica et rel. by $1.13- \pm 0.5$-fold $(P=.008$; $\mathrm{q}=0.144)$, Bacteroides stercoris et rel. by $0.83- \pm 0.2$-fold $(P=.011 ; \mathrm{q}=0.144)$ and Sutterella wadsworthia et rel.
Figure 1. Gut microbiota composition before (Pre) and after (Post) GOS and placebo intervention. $(A)$ Heat map of the bacterial groups at genus-like taxonomic level, whose change in abundance was significantly different $(q<$ 0.2 ) between GOS and placebo. For HITChip analysis, $\quad \log _{10}$-transformed signals were used as a proxy for bacterial logarithmic abundance. Color value shows $\log _{10^{-}}$ fold changes compared with baseline. Every column represents 1 individual participant. Differences between treatments were computed using a linear mixed model taking into account the effects of repeated measurements, treatment group, age, and body mass index. (B) Bifidobacterium relative abundance $\left(\log _{10}\right.$ signal intensity) as individual changes for the GOS group ( $\mathrm{n}=21$ ) and placebo group ( $n=23$ ), Pre and Post 12-week supplementation with GOS or placebo.

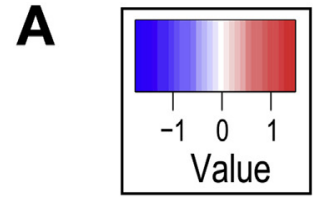

Placebo
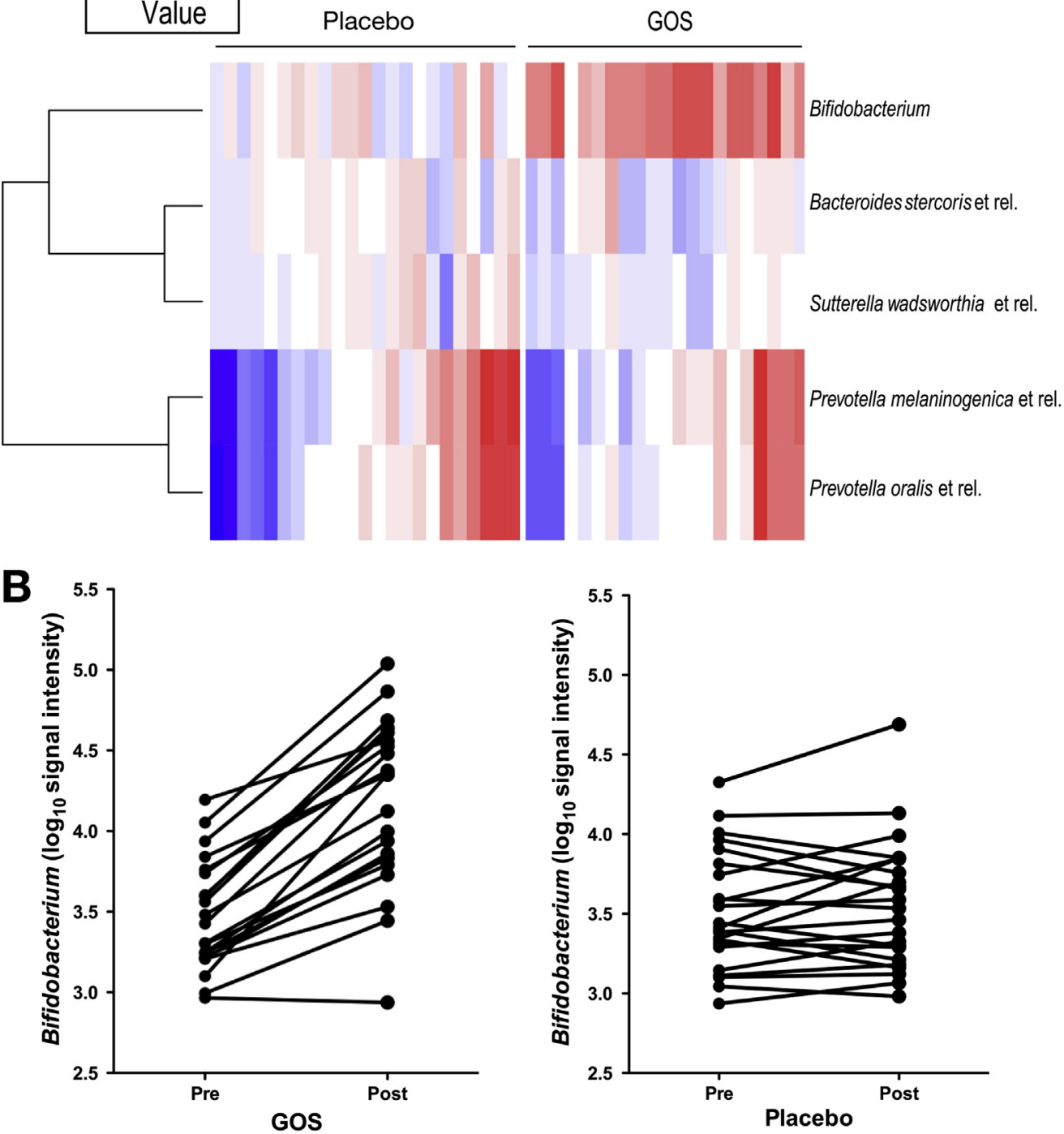
A

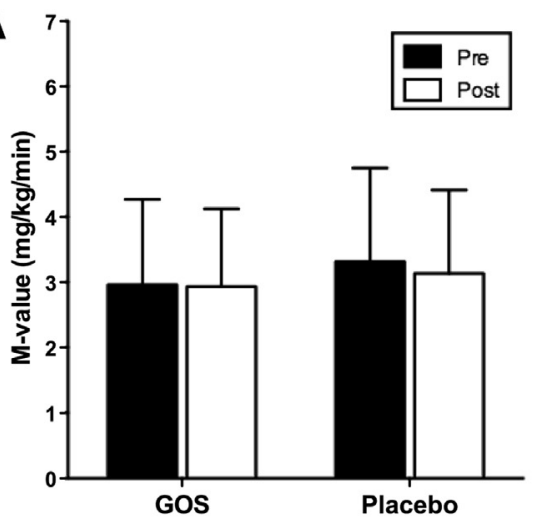

C

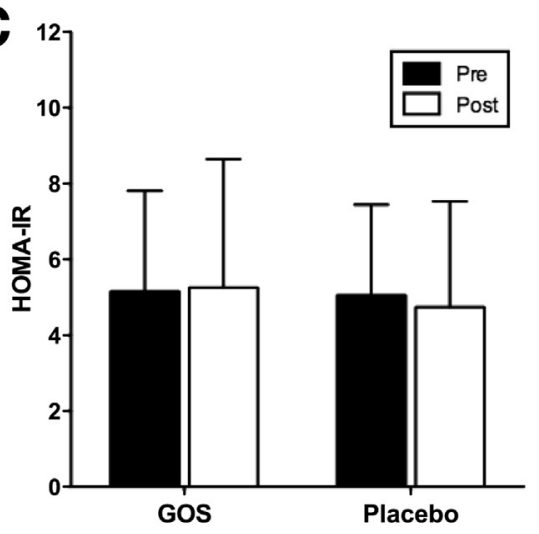

B
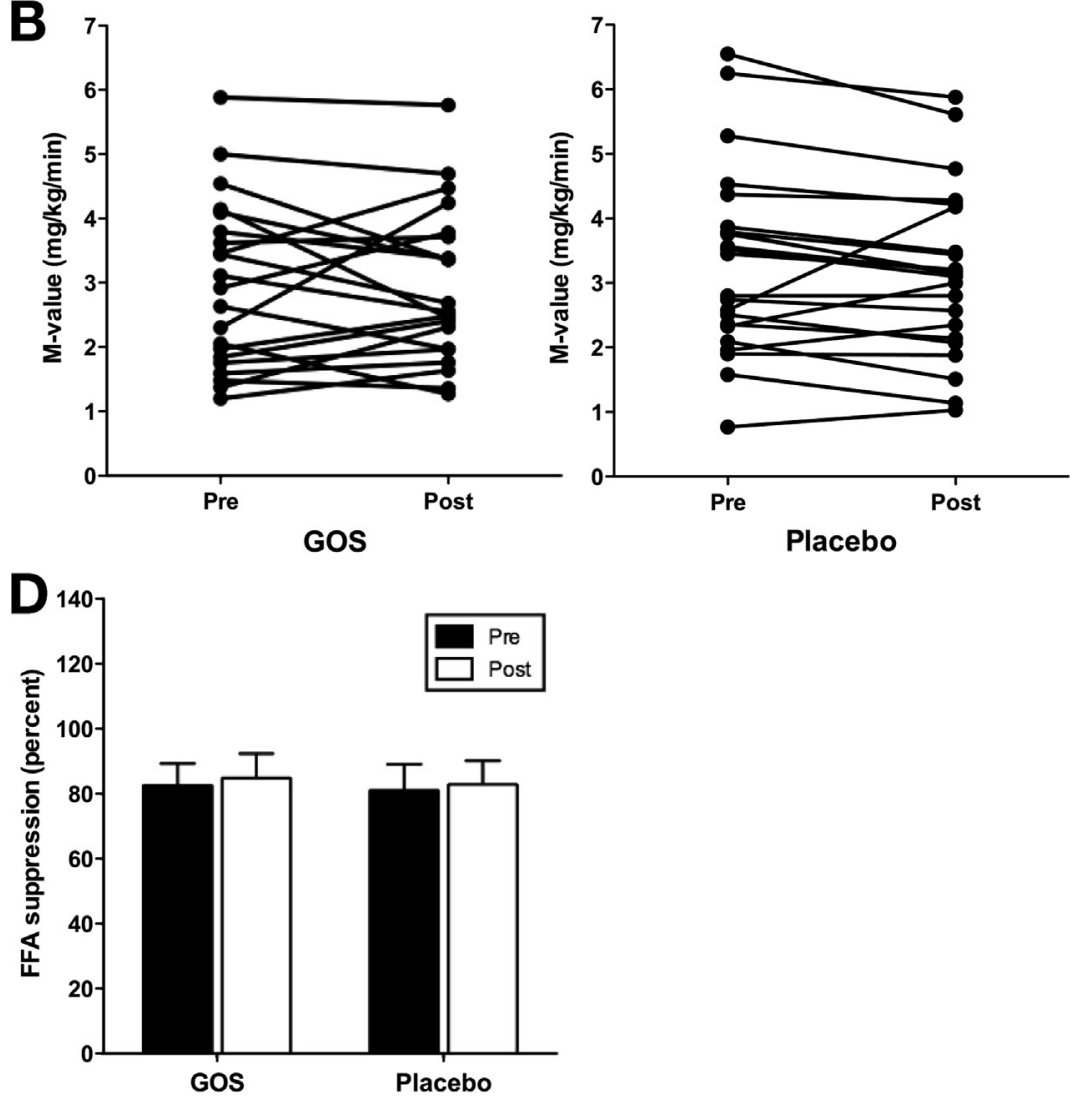

Figure 2. Insulin sensitivity before (Pre) and after (Post) GOS and placebo intervention. $(A) \mathrm{M}$ value given as means $\pm \mathrm{SD}(B)$ as individual changes for the GOS group $(n=21)$ and placebo group $(n=23)$ Pre and Post 12-week supplementation with GOS or placebo. (C) Homeostatic model assessment of insulin resistance (HOMA-IR) and (D) insulin-stimulated FFA suppression as a measure for adipose tissue insulin sensitivity Pre and Post 12-week supplementation with GOS or placebo. Values are given as means \pm SD and data were analyzed using 2-way repeated measures analysis of variance, with time (Pre, Post) and intervention (GOS, placebo). No significant effects were detected.

by $0.85- \pm 0.1$-fold $(P=.002 ; \mathrm{q}=0.116)$ (Figure $1 A)$. However these taxa all were affected to a much smaller degree than Bifidobacterium (Figure $1 A$ ) and showed a much less uniform pattern (Supplementary Figure $3 A$ ). The overall microbial richness $(P=.307)$ and diversity $(P=.626)$ were not different between groups (Supplementary Figure $3 B$ and $C$ ).

\section{Insulin Sensitivity}

Peripheral insulin sensitivity as assessed by the $M$ value was not changed after GOS treatment as compared with placebo $(P=.467)$ (Figure $2 A$ and $B$ ). The homeostatic model assessment of insulin resistance did not differ between treatments $(P=.598)$ (Figure 2C). In addition, insulin-stimulated FFA suppression, a measure for adipose tissue insulin sensitivity, was not affected by GOS as compared with placebo $(P=.808)$ (Figure $2 D)$.

\section{Short-Chain Fatty Acid Concentrations}

Fecal and plasma acetate, propionate, and butyrate concentrations did not differ between intervention groups (Figure 3).

\section{Food Intake and Physical Activity Records}

Energy intake, macronutrient, micronutrient, and dietary fiber intake, assessed using self-reported, 3-day food records, were not significantly different after 12 weeks of GOS intervention compared with placebo (Supplementary Table 1). Groups did not differ in physical activity levels as assessed via physical activity scores (Supplementary Table 1).

\section{Body Composition, BMI, and Body Weight}

BMI, body weight, body fat percentage, body fat mass, lean mass, and visceral adipose tissue mass were not affected significantly by GOS supplementation compared with placebo (Table 2).

\section{Circulating Metabolites, Hormones, and Inflammatory Profile}

No changes in fasting plasma glucose, insulin, glycerol, FFA, and TAG were observed between treatments (Table 3). Likewise, fasting plasma concentrations of leptin, PYY, GLP-1, and the inflammatory markers IL6, IL8, TNF- $\alpha$, and LBP were not affected significantly by the intervention as compared with placebo (Table 3). 

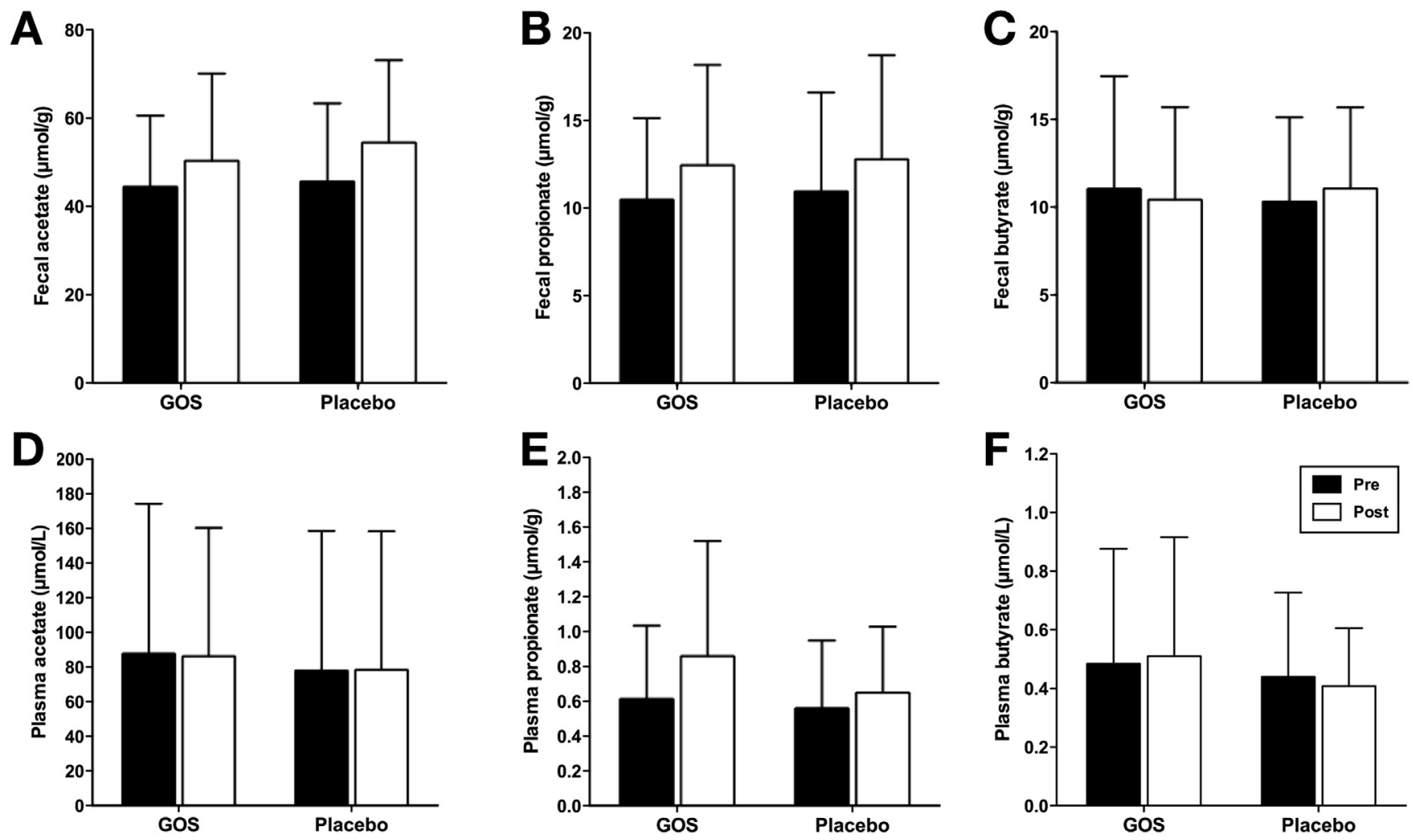

Figure 3. Fecal and plasma concentrations of short-chain fatty acids before (Pre) and after (Post) GOS and placebo intervention. $(A)$ Fecal acetate, $(B)$ propionate, and $(C)$ butyrate concentrations Pre and Post 12-week supplementation with GOS $(n=21)$ or placebo $(n=23)$. $(D)$ Plasma acetate, $(E)$ propionate, and $(F)$ butyrate concentrations Pre and Post 12-week supplementation with GOS $(n=21)$ or placebo $(n=23)$. Values are given as means \pm SD and data were analyzed using 2 -way repeated-measures analysis of variance, with time (Pre, Post) and intervention (GOS, placebo). No significant effects were determined.

\section{Energy Expenditure, Fat Oxidation, and Carbohydrate Oxidation}

GOS did not affect resting energy expenditure and insulin-mediated energy expenditure as compared with placebo treatment. In line, both resting as well as insulinstimulated respiratory quotient and fasting and insulinmediated fat and carbohydrate oxidation were not altered by GOS vs placebo (Table 4).

\section{Discussion}

In the present well-controlled human study, the effects of GOS supplementation on measurements of microbiota composition and functionality (SCFA) and detailed host metabolic phenotyping were combined. We showed that 12-week GOS supplementation markedly increased the abundance of fecal Bifidobacterium species without significant effects on overall microbial richness or diversity. Importantly, this specific bifidogenic effect neither translated into alterations of fecal or plasma SCFA concentrations, nor into changes in systemic concentrations of gut-derived hormones and systemic inflammatory markers. In addition, no significant alterations in peripheral and adipose tissue insulin sensitivity, body composition, energy and substrate metabolism, and circulating metabolites were found.
GOS supplementation ( $15 \mathrm{~g} /$ day) for 12 weeks increased the abundance of fecal Bifidobacterium, which is in accordance with previous studies, showing bifidogenic effects of

Table 2. Body Composition Before and After GOS and Placebo Intervention

\begin{tabular}{lllll}
\hline \multicolumn{1}{c}{ Variable } & & $\begin{array}{c}\text { GOS } \\
(\mathrm{n}=21)\end{array}$ & $\begin{array}{c}\text { Placebo } \\
(\mathrm{n}=23)\end{array}$ & $\begin{array}{c}P \\
\text { value }\end{array}$ \\
\hline Body mass index, $\mathrm{kg} / \mathrm{m}^{2}$ & Pre & $33.3 \pm 3.7$ & $32.3 \pm 3.5$ & .68 \\
& Post & $33.7 \pm 3.7$ & $32.7 \pm 3.3$ & \\
Body weight, $\mathrm{kg}$ & Pre & $98.4 \pm 11.9$ & $96.9 \pm 11.5$ & .69 \\
& Post & $99.5 \pm 12.3$ & $98.2 \pm 11.0$ & \\
Body fat, $\%$ & Pre & $36.8 \pm 7.8$ & $36.9 \pm 8.3$ & .17 \\
& Post & $37.1 \pm 7.6$ & $36.8 \pm 7.8$ & \\
Body fat, $\mathrm{kg}$ & Pre & $36.3 \pm 8.9$ & $36.0 \pm 9.0$ & .23 \\
& Post & $37.1 \pm 8.9$ & $36.3 \pm 8.9$ & \\
Lean mass, $\mathrm{kg}$ & Pre & $59.7 \pm 10.2$ & $58.9 \pm 9.5$ & .74 \\
Visceral fat, $g$ & Post & $60.7 \pm 10.7$ & $59.7 \pm 9.1$ & \\
& Pre & $932 \pm 353$ & $804 \pm 244$ & .89 \\
& Post & $928 \pm 343$ & $817 \pm 240$ &
\end{tabular}

NOTE. Values are given as means \pm SD, and data were analyzed using 2-way repeated-measures analysis of variance, with time (before [Pre], after [Post]) and intervention (GOS, $n=21$; placebo, $n=23$ ). No significant effects were detected. 
Table 3.Plasma Biochemistry Before and After GOS and Placebo Intervention

\begin{tabular}{|c|c|c|c|c|c|}
\hline \multicolumn{2}{|c|}{ Variable } & & \multirow[t]{2}{*}{$\operatorname{GOS}(n=21)$} & \multirow[t]{2}{*}{ Placebo $(n=23)$} & \multirow[t]{2}{*}{$P$ value } \\
\hline \multicolumn{3}{|l|}{ Plasma metabolites } & & & \\
\hline Glucose, $\mathrm{mmol} / \mathrm{L}$ & Fasting & Pre & $6.0 \pm 0.5$ & $5.8 \pm 0.4$ & .79 \\
\hline \multirow[t]{3}{*}{ TAG, $\mathrm{mmol} / \mathrm{L}$} & Fasting & Pre & $1.28 \pm 0.42$ & $1.17 \pm 0.45$ & .54 \\
\hline & & Post & $1.50 \pm 0.59$ & $1.31 \pm 0.51$ & \\
\hline & Steady-state & Pre & $1.19 \pm 0.54$ & $1.05 \pm 0.47$ & .71 \\
\hline \multirow{3}{*}{ Free glycerol, $\mu \mathrm{mol} / \mathrm{L}$} & & Post & $100 \pm 28$ & $98 \pm 25$ & \\
\hline & Steady-state & Pre & $50.3 \pm 19$ & $48.6 \pm 15$ & .18 \\
\hline & & Post & $46.2 \pm 13$ & $48.3 \pm 18$ & \\
\hline \multirow[t]{3}{*}{$\mathrm{FFA}, \mu \mathrm{mol} / \mathrm{L}$} & Fasting & Pre & $910 \pm 274$ & $848 \pm 208$ & .33 \\
\hline & & Post & $805 \pm 253$ & $809 \pm 214$ & \\
\hline & Steady-state & Pre & $119 \pm 59$ & $105 \pm 64$ & .71 \\
\hline \multirow[t]{2}{*}{$\mathrm{PYY}, \mathrm{pg} / \mathrm{mL}$} & Fasting & Pre & $50.8 \pm 11.8$ & $47.5 \pm 9.6$ & .88 \\
\hline & & Post & $53.4 \pm 12.2$ & $51.1 \pm 10.0$ & \\
\hline \multirow[t]{2}{*}{ Insulin, $m U / L$} & Fasting & Pre & $20.7 \pm 8.8$ & $19.1 \pm 17.3$ & .71 \\
\hline & & Post & $18.9 \pm 8.3$ & $18.3 \pm 10.1$ & \\
\hline \multirow[t]{2}{*}{ Leptin, $n g / m L$} & Fasting & Pre & $31.9 \pm 19.7$ & $33.4 \pm 20.8$ & .36 \\
\hline & & Post & $25.4 \pm 20.1$ & $28.8 \pm 21.0$ & \\
\hline \multicolumn{6}{|l|}{ Inflammatory markers } \\
\hline \multirow[t]{2}{*}{ LBP, $p g / m L$} & Fasting & Pre & $20.5 \pm 6.9$ & $26.4 \pm 19.3$ & .80 \\
\hline & & Post & $21.0 \pm 7.6$ & $25.4 \pm 13.9$ & \\
\hline \multirow[t]{2}{*}{ IL6, pg/mL } & Fasting & Pre & $0.82 \pm 0.30$ & $1.03 \pm 0.88$ & .59 \\
\hline & & Post & $0.85 \pm 0.48$ & $0.99 \pm 0.48$ & \\
\hline $\mathrm{IL} 8, \mathrm{pg} / \mathrm{mL}$ & Fasting & Pre & $4.28 \pm 1.11$ & $3.89 \pm 1.07$ & .35 \\
\hline
\end{tabular}

NOTE. Values are given as means \pm SD, and data were analyzed using 2-way repeated-measures analysis of variance, with time (before [Pre], after [Post]) and intervention (GOS, $n=21$; placebo, $n=23$ ). No significant effects were detected.

different types of GOS in infants and adults. ${ }^{13,14,18,35-37}$ However, GOS supplementation did not result in any changes in host substrate and energy metabolism in the obese prediabetic participants. Dependent on substrate availability, fermentation by Bifidobacterium mainly results in the production of lactate and acetate as end products. ${ }^{38}$ Indeed, fermentation of an identical type of GOS as used in the present study showed pronounced increases of acetate concentrations in the validated the Netherlands Organisation for applied scientific research (TNO) in vitro model of the colon (TNO-intestinal Model-2) ${ }^{17}$ Remarkably, we did not observe an increase in fecal or plasma acetate in vivo despite an average 5.0-fold increase in Bifidobacterium. Importantly, we measured fecal and plasma SCFA in fasted conditions and, therefore, cannot exclude that postprandial acetate concentration (ie, 4-8 h after GOS ingestion) may have been higher in the GOS group.

Upon colonic arrival, GOS is fermented quickly in the cecum and the proximal part of the colon. ${ }^{39}$ It is noteworthy that Boets et $\mathrm{al}^{40}$ indicated that a significant amount of colonically produced acetate is converted to other metabolites, in particular to butyrate, via microbial cross-feeding.
Interestingly, GOS supplementation for 3 weeks increased the production of butyrate in adults older than 50 years of age, but not of acetate, in a 3-stage in vitro fermentation model using their fecal inocula. ${ }^{41}$ The microbial conversion of acetate to butyrate would result in a diminished availability of acetate to metabolically active organs, such as the liver, skeletal muscle, or adipose tissue. The fact that butyrate is a primary energy source for colonocytes and is metabolized mainly in the colon, ${ }^{15}$ might explain why no alterations in fecal and in fasting plasma butyrate concentrations were observed in the present study. In addition, we previously showed that distal, but not proximal, colonic acetate infusions increased fat oxidation and increased circulating concentrations of acetate and PYY in overweight men. ${ }^{16}$ Distally applied acetate partly bypasses the liver via rectal veins, thereby directly reaching the systemic circulation, whereas more proximally administered acetate might be scavenged by the liver through portal drainage before it becomes systemically available. Thus, scavenging of acetate by the liver, the conversion of acetate into other metabolites, and the site of GOS fermentation may have led to an insufficient increase in systemic acetate concentrations to induce 
Table 4. Energy Expenditure and Substrate Oxidation Before and After GOS and Placebo Intervention

\begin{tabular}{|c|c|c|c|c|c|}
\hline Variable & & & GOS $(n=21)$ & Placebo $(n=23)$ & $P$ value \\
\hline Energy expenditure, $\mathrm{kJ} / \mathrm{min}$ & Fasting & $\begin{array}{l}\text { Pre } \\
\text { Post }\end{array}$ & $\begin{array}{l}5.47 \pm 0.74 \\
5.30 \pm 0.67\end{array}$ & $\begin{array}{l}5.30 \pm 0.63 \\
5.32 \pm 0.63\end{array}$ & .54 \\
\hline Energy expenditure, $\mathrm{kJ} / \mathrm{min}$ & Steady-state & $\begin{array}{l}\text { Pre } \\
\text { Post }\end{array}$ & $\begin{array}{l}5.37 \pm 0.71 \\
5.38 \pm 0.65\end{array}$ & $\begin{array}{l}5.20 \pm 0.62 \\
5.22 \pm 0.13\end{array}$ & .84 \\
\hline Fat oxidation, $\mathrm{g} / \mathrm{min}$ & Fasting & $\begin{array}{l}\text { Pre } \\
\text { Post }\end{array}$ & $\begin{array}{l}0.083 \pm 0.019 \\
0.076 \pm 0.020\end{array}$ & $\begin{array}{l}0.082 \pm 0.014 \\
0.078 \pm 0.020\end{array}$ & .24 \\
\hline Fat oxidation, $\mathrm{g} / \mathrm{min}$ & Steady-state & $\begin{array}{l}\text { Pre } \\
\text { Post }\end{array}$ & $\begin{array}{l}0.054 \pm 0.022 \\
0.047 \pm 0.021\end{array}$ & $\begin{array}{l}0.046 \pm 0.017 \\
0.045 \pm 0.021\end{array}$ & .17 \\
\hline Carbohydrate oxidation, $\mathrm{g} / \mathrm{min}$ & Fasting & $\begin{array}{l}\text { Pre } \\
\text { Post }\end{array}$ & $\begin{array}{l}0.086 \pm 0.037 \\
0.098 \pm 0.044\end{array}$ & $\begin{array}{l}0.072 \pm 0.033 \\
0.084 \pm 0.043\end{array}$ & .35 \\
\hline Carbohydrate oxidation, $\mathrm{g} / \mathrm{min}$ & Steady-state & $\begin{array}{l}\text { Pre } \\
\text { Post }\end{array}$ & $\begin{array}{l}0.147 \pm 0.048 \\
0.165 \pm 0.047\end{array}$ & $\begin{array}{l}0.158 \pm 0.045 \\
0.163 \pm 0.052\end{array}$ & .24 \\
\hline Respiratory quotient & Fasting & $\begin{array}{l}\text { Pre } \\
\text { Post }\end{array}$ & $\begin{array}{l}0.79 \pm 0.03 \\
0.80 \pm 0.04\end{array}$ & $\begin{array}{l}0.78 \pm 0.03 \\
0.79 \pm 0.04\end{array}$ & .97 \\
\hline Respiratory quotient & Steady-state & $\begin{array}{l}\text { Pre } \\
\text { Post }\end{array}$ & $\begin{array}{l}0.84 \pm 0.04 \\
0.86 \pm 0.05\end{array}$ & $\begin{array}{l}0.86 \pm 0.04 \\
0.87 \pm 0.04\end{array}$ & .20 \\
\hline
\end{tabular}

NOTE. Values are given as means $\pm S D$, and data were analyzed using 2-way repeated-measures analysis of variance, with time (before [Pre], after [Post]) and intervention (GOS, $n=21$; placebo, $n=23$ ). No significant effects were detected.

pronounced metabolic effects. Therefore, future research should focus on strategies to increase acetate concentrations specifically in the distal part of the colon in the longer term. Such strategies could include the production of slow-fermentable acetogenic foods. ${ }^{42}$

The marked GOS-induced microbial changes without impact on energy and substrate metabolism, inflammatory profile, and insulin sensitivity in the present study are in contrast to some, ${ }^{13-15,43}$ but not all, ${ }^{15,44}$ previous human studies using GOS or fructo-oligosaccharides. A cross-over study by Vulevic et $\mathrm{al}^{13}$ indicated that a 12 -week supplementation of a GOS mixture (5.5 g/day) decreased systemic inflammatory markers, fasting insulin, cholesterol, and triglyceride concentrations in overweight participants. ${ }^{13}$ In addition, after GOS treatment, lipopolysaccharidestimulated production of IL6, IL1 $\beta$, and TNF- $\alpha$ was lowered from isolated peripheral blood mononuclear cells in an ex vivo experiment. ${ }^{14}$ One of the explanations for the different metabolic outcomes between these studies and the present study might be the difference in population, which differed with respect to age and metabolic status. We included prediabetic overweight/obese men and postmenopausal women aged between 45 and 70 years in the present study, whereas Vulevic et al ${ }^{13,14}$ investigated either a metabolically healthy elderly population, or overweight, but more insulin-sensitive and younger adults. Aging, obesity, and insulin resistance have been associated with alterations in gut microbiota composition, and microbial richness and diversity, as well as with a reduction of Bifidobacterium specifically, and thus possibly with an altered metabolic response upon prebiotic treatment. ${ }^{45-48}$ In addition, recent studies have suggested that microbiota from obese patients have a reduced fermentation capacity compared with microbiota from lean subjects. ${ }^{49,50}$ However, there remain inconsistencies, especially between human studies, regarding the aforementioned altered features of the microbiome. ${ }^{51}$ Furthermore, compared with animal experiments, the human microbiome is exposed to fundamentally different environmental factors that extend beyond the intervention alone such as heterogeneity of human (sub)population with regard to genetics, lifestyle, and diet. ${ }^{52}$ Overall, the metabolic imbalance and related progressed dysbiosis in our obese prediabetic population might have hampered an improved metabolic effect via an altered microbial composition and activity. Therefore, the relevance of specific gut microbiota manipulation between different metabolic phenotypes (ie, insulin-resistant vs insulin-sensitive human beings), should be investigated in more detail in future studies.

When we compared the Bifidobacterium of our study population with that of healthy lean adults, the baseline abundance of Bifidobacterium was markedly lower in our obese population, but reached slightly higher abundance after GOS intervention compared with this healthy, untreated population (unpublished data, Laboratory of Microbiology, Wageningen UR, Wageningen, The Netherlands). In addition, we found overall small and inconsistent changes in the taxa Prevotella oralis et rel., Prevotella melaninogenica et rel., Bacteroides stercoris et rel., and Sutterella wadsworthia et rel. upon GOS ingestion compared with the placebo group. This in vivo data add to previous in vitro studies showing that GOS feeding is highly specific at selectively enhancing bifidobacteria without consistently increasing or decreasing other specific bacterial lineages. ${ }^{19}$ It is possible that the high dosage of GOS in this study, $15 \mathrm{~g} /$ day compared with other studies using $5.5 \mathrm{~g} /$ day, ${ }^{13,14}$ resulted in more cross-feeding between specific members of the Bacteroidetes phylum and Bifidobacterium because of the increased availability of substrate. This provides an opportunity for other bacterial species to use GOS as a source and to grow upon GOS supplementation. This is in line with a recent study indicating that supplementation of GOS $15 \mathrm{~g} /$ day impacted at least 11 microbial genera, including Bifidobacterium. ${ }^{53}$ The small increase and 
particularly inconsistent pattern of increase, however, makes it highly unlikely that changes in these specific taxa explain the lack of effects on the metabolic outcomes in the present study.

In conclusion, we showed in this well-controlled study, in which participants were phenotyped in detail, that 12-week supplementation of GOS in prediabetic men and women increased the abundance of Bifidobacterium, however, no alterations in plasma or fecal SCFA, peripheral insulin sensitivity, energy and substrate metabolism, and low-grade inflammation were observed. Hence, the present study implies that a considerable diet-related increase in Bifidobacterium does not significantly affect insulin sensitivity and parameters of the host substrate and energy metabolism immediately in a prediabetic population with overweight or obesity.

\section{Supplementary Material}

Note: To access the supplementary material accompanying this article, visit the online version of Gastroenterology at www.gastrojournal.org, and at http://dx.doi.org/10.1053/ j.gastro.2017.03.051.

\section{References}

1. Delzenne NM, Cani PD, Everard A, et al. Gut microorganisms as promising targets for the management of type 2 diabetes. Diabetologia 2015;58:2206-2217.

2. Diamant $M$, Blaak E, De Vos W. Do nutrient-gut -microbiota interactions play a role in human obesity, insulin resistance and type 2 diabetes? Obes Rev 2011; 12:272-281.

3. Clemente JC, Ursell LK, Parfrey LW, et al. The impact of the gut microbiota on human health: an integrative view. Cell 2012;148:1258-1270.

4. Robertson MD, Bickerton AS, Dennis AL, et al. Insulinsensitizing effects of dietary resistant starch and effects on skeletal muscle and adipose tissue metabolism. Am J Clin Nutr 2005;82:559-567.

5. Vrieze A, Out C, Fuentes S, et al. Impact of oral vancomycin on gut microbiota, bile acid metabolism, and insulin sensitivity. J Hepatol 2014;60:824-831.

6. Vrieze A, Van Nood E, Holleman F, et al. Transfer of intestinal microbiota from lean donors increases insulin sensitivity in individuals with metabolic syndrome. Gastroenterology 2012;143:913-916.

7. Hulston CJ, Churnside AA, Venables MC. Probiotic supplementation prevents high-fat, overfeeding-induced insulin resistance in human subjects. Br J Nutr 2015; 113:596-602.

8. Mikkelsen $\mathrm{KH}$, Allin KH, Knop FK. Effect of antibiotics on gut microbiota, glucose metabolism and bodyweight regulation-a review of the literature. Diabetes Obes Metab 2016;18:444-453.

9. Kellow NJ, Coughlan MT, Reid CM. Metabolic benefits of dietary prebiotics in human subjects: a systematic review of randomised controlled trials. Br J Nutr 2014; 111:1147-1161.
10. Ruan Y, Sun J, He J, et al. Effect of probiotics on glycemic control: a systematic review and meta-analysis of randomized, controlled trials. PLoS One 2015; 10:e0132121.

11. Roberfroid M, Gibson GR, Hoyles L, et al. Prebiotic effects: metabolic and health benefits. $\mathrm{Br} J$ Nutr 2010; 104:S1-S63.

12. Delzenne NM, Neyrinck AM, Cani PD. Gut microbiota and metabolic disorders: how prebiotic can work? $\mathrm{Br} J$ Nutr 2013;109:S81-S85.

13. Vulevic J, Juric A, Tzortzis G, et al. A mixture of transgalactooligosaccharides reduces markers of metabolic syndrome and modulates the fecal microbiota and immune function of overweight adults. J Nutr 2013; 143:324-331.

14. Vulevic J, Drakoularakou A, Yaqoob P, et al. Modulation of the fecal microflora profile and immune function by a novel trans-galactooligosaccharide mixture (B-GOS) in healthy elderly volunteers. Am J Clin Nutr 2008;88: 1438-1446.

15. Canfora EE, Jocken JW, Blaak EE. Short-chain fatty acids in control of body weight and insulin sensitivity. Nat Rev Endocrinol 2015;11:577-591.

16. van der Beek CM, Canfora EE, Lenaerts K, et al. Distal, not proximal, colonic acetate infusions promote fat oxidation and improve metabolic markers in overweight/ obese men. Clin Sci (Lond) 2016;130:2073-2082.

17. Maathuis AJ, van den Heuvel EG, Schoterman MH, et al. Galacto-oligosaccharides have prebiotic activity in a dynamic in vitro colon model using a 13C-labeling technique. J Nutr 2012;142:1205-1212.

18. Holscher HD, Faust KL, Czerkies LA, et al. Effects of prebiotic-containing infant formula on gastrointestinal tolerance and fecal microbiota in a randomized controlled trial. JPEN J Parenter Enteral Nutr 2012;36:95S-105S.

19. Davis LM, Martínez I, Walter J, et al. Barcoded pyrosequencing reveals that consumption of galactooligosaccharides results in a highly specific bifidogenic response in humans. PLoS One 2011;6:e25200.

20. Pokusaeva K, Fitzgerald GF, van Sinderen D. Carbohydrate metabolism in Bifidobacteria. Genes Nutr 2011; 6:285-306.

21. Wendel-Vos GW, Schuit AJ, Saris WH, et al. Reproducibility and relative validity of the short questionnaire to assess health-enhancing physical activity. J Clin Epidemiol 2003;56:1163-1169.

22. DeFronzo RA, Tobin JD, Andres R. Glucose clamp technique: a method for quantifying insulin secretion and resistance. Am J Physiol Gastrointest Liver Physiol 1979; 237:G214-G223.

23. Jaquet D, Gaboriau A, Czernichow $P$, et al. Insulin resistance early in adulthood in subjects born with intrauterine growth retardation. J Clin Endocrinol Metab 2000;85:1401-1406.

24. Weir JB. New methods for calculating metabolic rate with special reference to protein metabolism. J Physiol 1949; 109:1-9.

25. Frayn KN. Calculation of substrate oxidation rates in vivo from gaseous exchange. J Appl Physiol 1983;55: 628-634. 
26. Orskov C, Rabenhoj L, Wettergren A, et al. Tissue and plasma concentrations of amidated and glycineextended glucagon-like peptide I in humans. Diabetes 1994;43:535-539.

27. García-Villalba R, Giménez-Bastida JA, García-Conesa MT, et al. Alternative method for gas chromatography-mass spectrometry analysis of short-chain fatty acids in faecal samples. J Sep Sci 2012;35:1906-1913.

28. van Eijk HM, Bloemen JG, Dejong $\mathrm{CH}$. Application of liquid chromatography-mass spectrometry to measure short chain fatty acids in blood. J Chromatogr B Analyt Technol Biomed Life 2009;877:719-724.

29. Salonen A, Nikkilä J, Jalanka-Tuovinen J, et al. Comparative analysis of fecal DNA extraction methods with phylogenetic microarray: effective recovery of bacterial and archaeal DNA using mechanical cell lysis. J Microbiol Methods 2010;81:127-134.

30. Rajilić-Stojanović M, Heilig HG, Molenaar D, et al. Development and application of the human intestinal tract chip, a phylogenetic microarray: analysis of universally conserved phylotypes in the abundant microbiota of young and elderly adults. Environ Microbiol 2009;11:1736-1751.

31. Lahti L, Elo LL, Aittokallio T, et al. Probabilistic analysis of probe reliability in differential gene expression studies with short oligonucleotide arrays. IEEE/ACM Trans Comput Biol Bioinform 2011;8:217-225.

32. Bates D, Maechler M, Bolker B, et al. Package 'Ime4'. Convergence 2015;12:1.

33. Bates D, Mächler M, Bolker B, et al. Fitting linear mixedeffects models using Ime4. J Stat Software 2015;67:1-48.

34. Oksanen J, Blanchet FG, Kindt R, et al. Package 'vegan'. Community ecology package, version 2, 2013.

35. Depeint F, Tzortzis G, Vulevic J, et al. Prebiotic evaluation of a novel galactooligosaccharide mixture produced by the enzymatic activity of Bifidobacterium bifidum NCIMB 41171, in healthy humans: a randomized, double-blind, crossover, placebo-controlled intervention study. Am J Clin Nutr 2008;87:785-791.

36. Sierra C, Bernal M-J, Blasco J, et al. Prebiotic effect during the first year of life in healthy infants fed formula containing GOS as the only prebiotic: a multicentre, randomised, double-blind and placebo-controlled trial. Eur J Nutr 2015;54:89-99.

37. Vulevic J, Juric A, Walton GE, et al. Influence of galactooligosaccharide mixture (B-GOS) on gut microbiota, immune parameters and metabonomics in elderly persons. Br J Nutr 2015;114:586-595.

38. Rossi M, Corradini C, Amaretti A, et al. Fermentation of fructooligosaccharides and inulin by bifidobacteria: a comparative study of pure and fecal cultures. Appl Environ Microbiol 2005;71:6150-6158.

39. Slavin J. Fiber and prebiotics: mechanisms and health benefits. Nutrients 2013:5:1417-1435.

40. Boets E, Gomand SV, Deroover L, et al. Systemic availability and metabolism of colonic derived short chain fatty acids in healthy subjects: a stable isotope study. J Physiol 2017:595:541-555.

41. Walton GE, van den Heuvel EG, Kosters $M H$, et al. A randomised crossover study investigating the effects of galacto-oligosaccharides on the faecal microbiota in men and women over 50 years of age. Br J Nutr 2012; 107:1466-1475.

42. Kaur A, Rose DJ, Rumpagaporn $P$, et al. In vitro batch fecal fermentation comparison of gas and short-chain fatty acid production using "slowly fermentable" dietary fibers. J Food Sci 2011;76:H137-H142.

43. Parnell JA, Reimer RA. Weight loss during oligofructose supplementation is associated with decreased ghrelin and increased peptide $Y Y$ in overweight and obese adults. Am J Clin Nutr 2009;89:1751-1759.

44. Dewulf E, Cani P, Claus S, et al. Insight into the prebiotic concept: lessons from an exploratory, double blind intervention study with inulin-type fructans in obese women. Gut 2013;62:1112-1121.

45. O'Toole PW, Jeffery IB. Gut microbiota and aging. Science 2015;350:1214-1215.

46. Ley RE. Obesity and the human microbiome. Curr Opin Gastroenterol 2010;26:5-11.

47. Tremaroli V, Bäckhed F. Functional interactions between the gut microbiota and host metabolism. Nature 2012; 489:242-249.

48. Saraswati S, Sitaraman R. Aging and the human gut microbiota-from correlation to causality. Front Microbiol 2015;5:764.

49. Ridaura VK, Faith JJ, Rey FE, et al. Gut microbiota from twins discordant for obesity modulate metabolism in mice. Science 2013;341:1241214.

50. Khan MT, Nieuwdorp M, Bäckhed F. Microbial modulation of insulin sensitivity. Cell Metab 2014;20:753-760.

51. Walters WA, Xu Z, Knight R. Meta-analyses of human gut microbes associated with obesity and IBD. FEBS Lett 2014;588:4223-4233.

52. Hermes G, Zoetendal E, Smidt H. Molecular ecological tools to decipher the role of our microbial mass in obesity. Benef Microbes 2014;6:61-81.

53. Azcarate-Peril MA, Ritter AJ, Savaiano D, et al. Impact of short-chain galactooligosaccharides on the gut microbiome of lactose-intolerant individuals. Proc Natl Acad Sci U S A 2017;114:E367-E375.

Author names in bold designate shared co-first authorship.

Received December 15, 2016. Accepted March 31, 2017.

Reprint requests

Address requests for reprints to: Emanuel E. Canfora, PhD, Department of Human Biology, Maastricht University Medical Centre+, PO Box 616, 6200 Maastricht, The Netherlands. e-mail: Emanuel.canfora@maastrichtuniversity.nl; fax: $+31(0) 433670976$.

\section{Acknowledgments}

The authors would kindly like to thank the study volunteers, as well as Annemarie van Bijnen, Bas Boonen, Yvonne Essers, M'hammed Hadfoune, Gabby Hul, Paul Schoffelen, Wendy Sluijsman, and Jos Stegen for their excellent technical support.

\section{Conflicts of interest}

The authors disclose no conflicts.

\section{Funding}

The research was funded by TI Food and Nutrition (project GH003), a publicprivate partnership on precompetitive research in food and nutrition. The funders had no role in the study design, data collection and analysis, decision to publish, or preparation of the manuscript. 


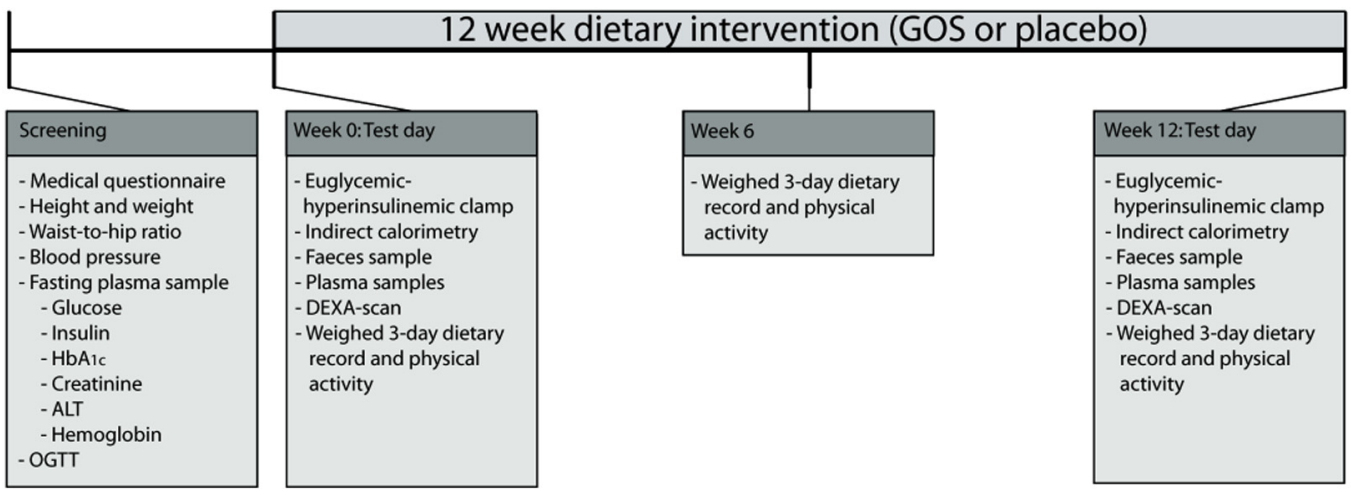

Supplementary Figure 1. Outline of study design. ALT, alanine transaminase, DEXA, dual energy X-ray absorptiometryscanning; $\mathrm{HbA}_{1 \mathrm{c}}$, glycated hemoglobin; OGTT, oral glucose tolerance test.

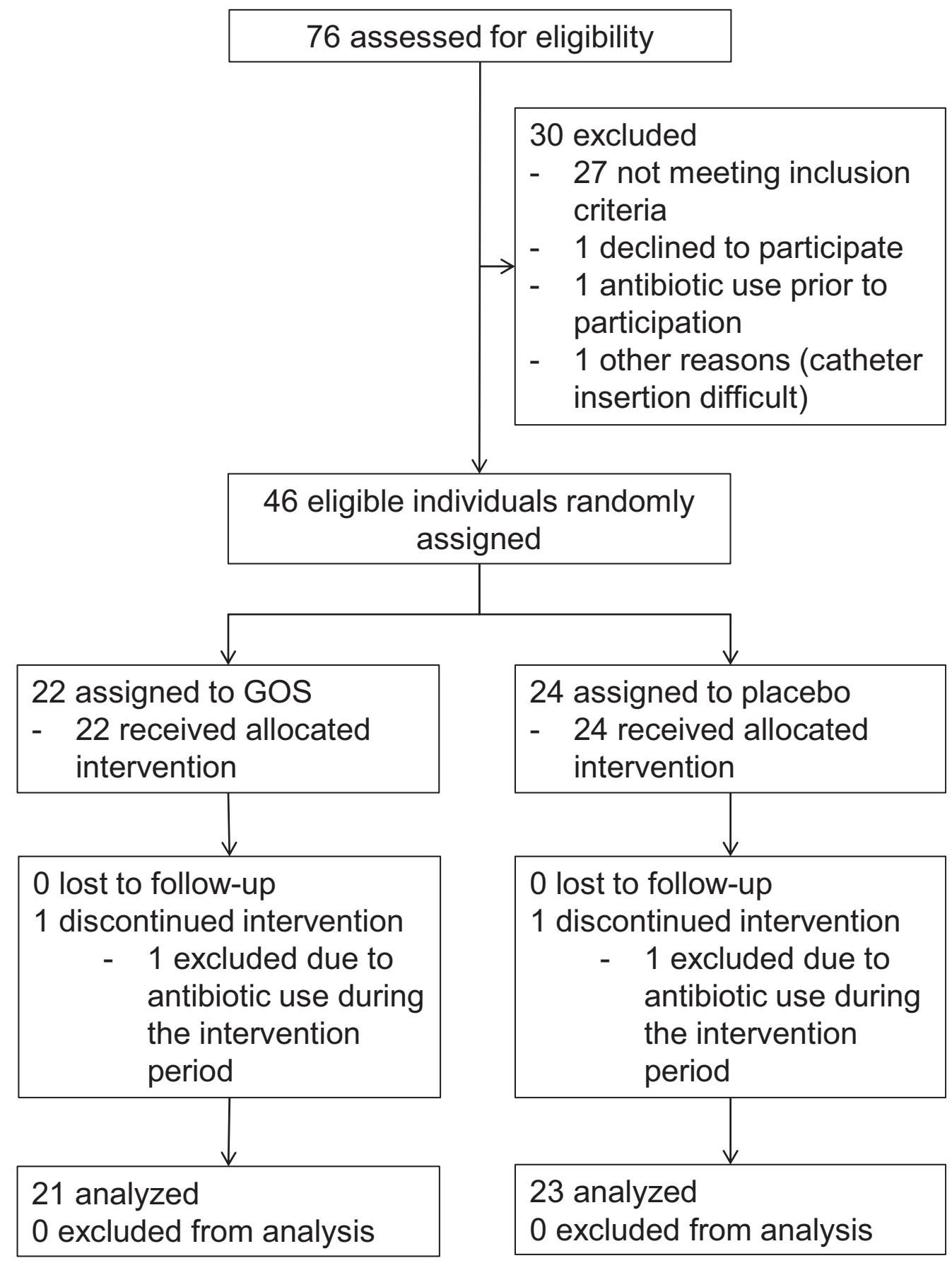

Supplementary Figure 2. Flow diagram of human participants included in this study. 
A

Prevotella.oralis.et.rel.

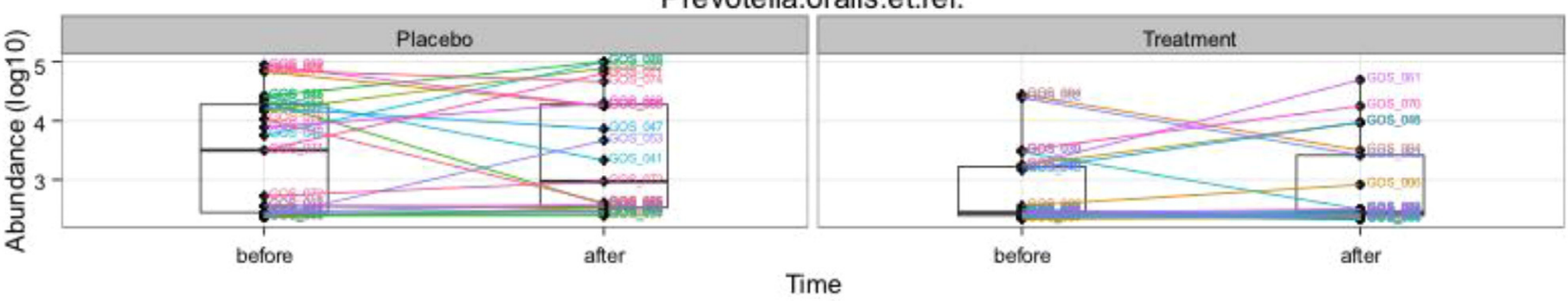

Prevotella.melaninogenica.et.rel.

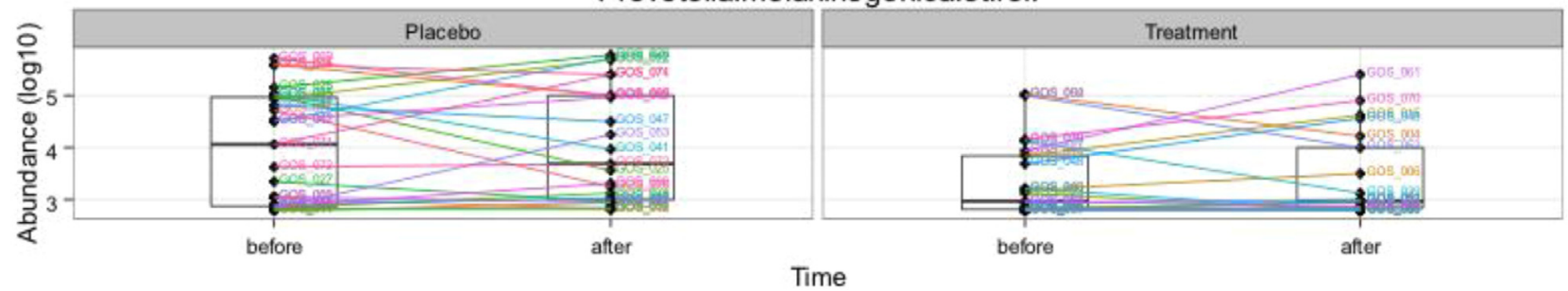

Bacteroides.stercoris.et.rel.

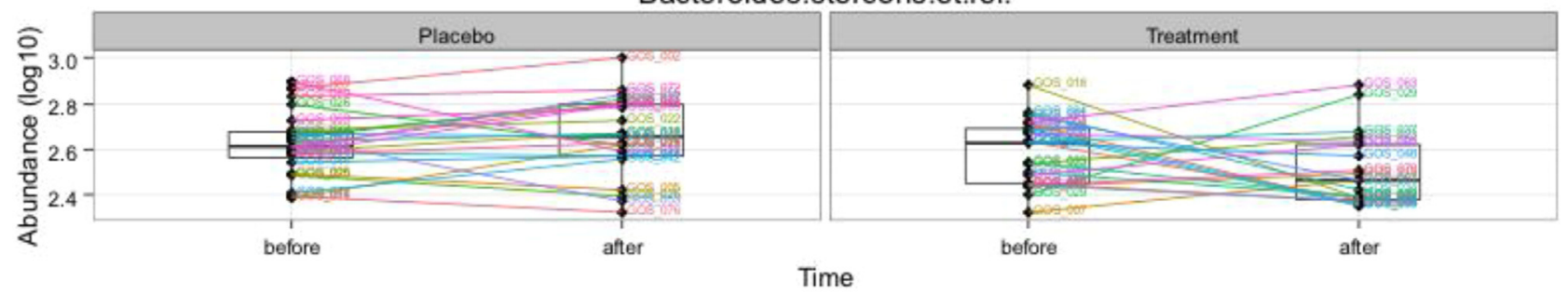

Sutterella.wadsworthia.et.rel.

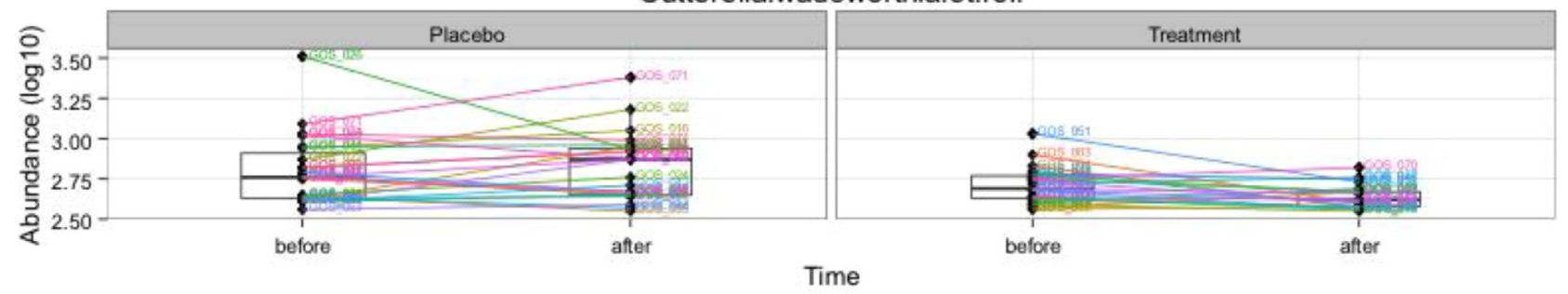

B

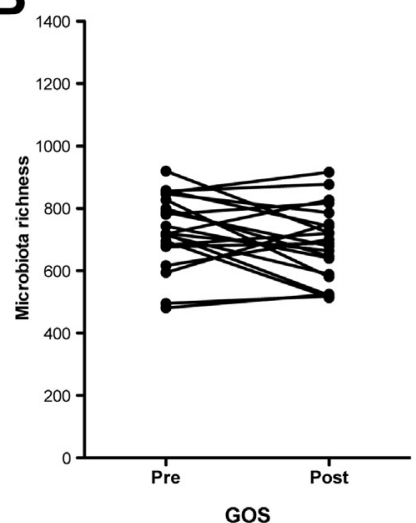

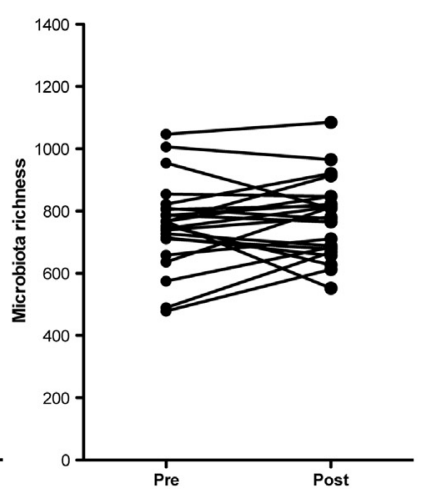

Placebo
C
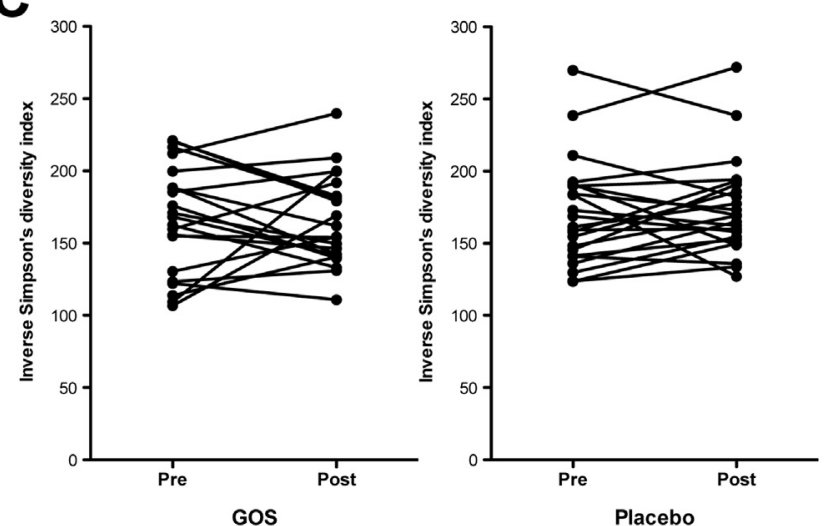

Supplementary Figure 3. Gut microbiota composition before (Pre) and after (Post) GOS and placebo intervention. For HITChip analysis, $\log _{10}$-transformed signals were used as a proxy for bacterial logarithmic abundance. (A) Prevotella oralis, Prevotella melaninogenica, Bacteroides stercoris, and Sutterella wadsworthia relative abundance ( $\log _{10}$ signal intensity) as individual changes for the GOS group $(n=21)$ and placebo group $(n=23)$, pre and post 12-week supplementation with GOS or placebo. (B) Microbial richness as individual changes for the GOS group $(n=21)$ and placebo group $(n=23)$, pre and post 12-week supplementation with GOS or placebo. (C) Inverse Simpson diversity index (microbial diversity) as individual changes for the GOS group $(n=21)$ and placebo group $(n=23)$, pre and post 12-week supplementation with GOS or placebo. 
Supplementary Table 1. Food Intake and Physical Activity Scores Before and After GOS and Placebo Intervention

\begin{tabular}{|c|c|c|c|c|c|c|c|}
\hline \multirow[b]{2}{*}{ Time } & \multicolumn{3}{|c|}{ GOS $(n=21)$} & \multicolumn{3}{|c|}{ Placebo $(n=23)$} & \multirow[b]{2}{*}{$P$ value } \\
\hline & Baseline & Week 6 & Week 12 & Baseline & Week 6 & Week 12 & \\
\hline Energy intake, kcal & $2456 \pm 758$ & $2470 \pm 665$ & $2226 \pm 504$ & $2235 \pm 636$ & $2282 \pm 539$ & $2198 \pm 628$ & .513 \\
\hline Fat intake, $g$ & $101 \pm 44$ & $83 \pm 29$ & $79 \pm 32$ & $87 \pm 34$ & $78 \pm 29$ & $78 \pm 34$ & .456 \\
\hline Carbohydrate intake, $g$ & $256 \pm 92$ & $262 \pm 89$ & $247 \pm 66$ & $242 \pm 73$ & $252 \pm 66$ & $243 \pm 75$ & .873 \\
\hline Protein intake, $g$ & $104 \pm 39$ & $112 \pm 26$ & $105 \pm 18$ & $88 \pm 21$ & $97 \pm 21$ & $98 \pm 19$ & .589 \\
\hline Dietary fiber intake (without GOS), $g$ & $20.9 \pm 5.1$ & $19.8 \pm 7.0$ & $18.5 \pm 4.9$ & $21.6 \pm 5.8$ & $21.5 \pm 5.9$ & $19.4 \pm 5.5$ & .912 \\
\hline Meeting Dutch guidelines for physical activity, $\mathrm{n}$ & 18 & 18 & 18 & 17 & 19 & 18 & .740 \\
\hline Light physical activity, $\min / w k$ & $1009 \pm 787$ & $1188 \pm 867$ & $1342 \pm 1034$ & $1342 \pm 992$ & $1090 \pm 886$ & $1352 \pm 1142$ & .310 \\
\hline Moderate physical activity, $\mathrm{min} / \mathrm{wk}$ & $657 \pm 533$ & $581 \pm 336$ & $765 \pm 528$ & $703 \pm 593$ & $912 \pm 814$ & $743 \pm 586$ & .114 \\
\hline Vigorous physical activity, $\min / w k$ & $53 \pm 94$ & $52 \pm 137$ & $84 \pm 167$ & $63 \pm 129$ & $75 \pm 183$ & $43 \pm 105$ & .223 \\
\hline
\end{tabular}

NOTE. Values are given as means $\pm S D$, and data were analyzed using a 2-way repeated-measures analysis of variance, with time (before, after) and intervention (GOS, $n=21$; placebo, $n=23$ ). 